3

4

5

6

Will 'we' continue to exercise? The associations between group identification, identity leadership, and relational identification on group exercise class adherence 


\begin{abstract}
The present study sought to provide support for the roles of both the social identity approach (group identification and identity leadership) and relational identification in adherence to group exercise classes. One hundred and twenty U.K. based group exercise class attendees completed an online survey in a cross-sectional design. Group identification, perceptions of identity leadership behaviour, and relational identification were not significantly associated with length of class attendance. However, both identity leadership behaviour of the class instructor and ingroup affect (measured as an element of multidimensional group identification), were significantly associated with expected likelihood of continued class participation. For every 1 unit increase in the identity leadership and ingroup affect measures respectively, participants were 1.9 and 2.0 times more likely to be 'at or near $100 \%$ ' likely to continue vs not. Social identity variables were not associated with how long exercisers had been attending class, but identity leadership and ingroup affect are positive influencers of expected future adherence. Further research into the social identity approach and identity leadership behaviour regards exercise class attendance tenure vs volume is warranted and is likely to benefit from the use of multi-dimensional group identification measures.
\end{abstract}

KEYWORDS: Group Dynamics, Health, Behaviour Change, Physical Activity 


\section{Will 'We' Continue to Exercise? The Associations between Group Identification, Identity Leadership, and Relational Identification on Group Exercise Class Adherence}

Physical activity is associated with a wide range of health benefits, including reduced risk of cardiovascular disease, type 2 diabetes, cancers, and depression [1]. While it is recommended that adults engage in 150 minutes of moderate intensity exercise each week, $41 \%$ of those aged $40-60$ are undertaking nowhere this level, failing to walk briskly for even 10 minutes a month [2]. Adherence to new exercise programs is also poor, and around half of those who begin exercising drop out within the first six months [3]. The physical and psychological benefits of regular exercise make encouraging participation and understanding factors linked to adherence of great importance. There is a need to ensure that adults not only start exercising, but also continue to participate. Group exercise classes have been highlighted as a potential gateway to participation, with almost one third of people attending having been previously inactive [4]. With this in mind, group exercise classes offer a valuable avenue for research to advance our understanding of how continued attendance in these settings might be encouraged.

\section{The Social Identity Approach}

It has been suggested that the social identity approach provides crucial and unique social processes to understand and influence physical activity participation [5-7]. While the social identity approach has been applied across a variety of contexts including within organisations [8], and sport [5,9], research with regard to its relevance to exercise remains limited (exceptions [6,7]). The social identity approach comprises two theories; social identity theory [10] and self-categorisation theory [11]. Social identity theory posits that individuals have personal identities and also social identities related to the groups (e.g., an exercise class) to which they see themselves as part. A social identity may be considered as a person's sense of self that is based on their group membership(s). Self-categorisation theory 
describes the process by which individuals' move from a personal to a social identity ('me' to 'we') termed 'depersonalisation'. Once 'depersonalised' it is suggested that an individual will reference the values and norms of the group (as opposed to their own) to inform their behaviour. In this way, it is possible to hypothesise that by identifying as part of a group that values regular exercise (e.g., an exercise class) an individual's behaviour may be affected in the form of increased adherence. Accordingly, group (social) identification, or an individual's sense of belonging or commitment to a group, may relate to length of class participation and/or intention to continue to participate. This is not of course to suggest that personal identity is unimportant in this regard. Indeed, running role identity may be more important than running group identity in terms of adherence in the face of group disbandment [12], and the development of group and personal identities in relation to exercise may be intertwined [13]. Examination of this however, falls beyond the scope of the present study.

The idea that group identification may engender exercise participation and adherence is not new in itself, with research evidence, including meta-analysis, supporting this [14-16]. In general, participants reporting to identify more strongly with a group for which exercise is a norm also report increased intention to exercise [16] and groups have been shown as beneficial in terms of exercise adherence [14]. More recently, studies have adopted the social identity approach as a theoretical standpoint. Stevens et al. [7,17] demonstrated a relationship between levels of group identification and exercise attendance rates (in group exercise classes and parkrun). Whilst undoubtedly promising research in terms of the applicability of the social identity approach to group exercise contexts, these studies adopted attendance measures of frequency/volume (e.g., Stevens et al. [7] measured percentage of total sessions attended in a single week). To our knowledge, no studies to date have specifically examined the social identity approach regards exercise classes and adherence in terms of tenure, i.e. how long a person has attended a given class. Maintenance presents a 
key area of difficulty in encouraging health behaviour change, such as exercise participation

[18]. By examining tenure, we have an opportunity to better understand factors relating to continued adherence and encourage long-term participation. This may not be fully comprehended through focus on frequency/volume of attendance in a single week.

A further opportunity is presented with regards the conceptualisation of group identification. Beauchamp [19] highlighted the influential role of identification within exercise groups as a way to promote adherence and advocated a need for greater understanding. Whilst recent studies examining group identification in exercise classes have used a global measure of identification [7,20], research evidence across disciplines has suggested that group identification may in fact be multi-dimensional $[21,22]$. Cameron's [23] three-factor model of social identity developed in social psychology has been empirically supported in sport settings (e.g., [21]). The model proposes two cognitive elements of identity (ingroup ties and cognitive centrality) and an affective element (ingroup affect). Although an alternate form of physical activity to exercise, in a sport context support has been shown for the three factors relating to different outcomes, such as initiative, and pro/anti-social behaviour $[21,24]$. It is therefore plausible to posit that each factor may relate differently to behaviours within an exercise context, for example, the behaviour of 'adhering to an exercise class', meaning investigation may add novel and important insight.

\section{The Social Identity Approach to Leadership}

Group exercise class instructors may also have a key role to play in regard to attendance [25] often planning and advertising classes as well as providing instruction. The application of the social identity approach to physical activity has garnered interest in how leaders (e.g. class instructors) in these settings may influence physical activity behaviour $[7,9,20,26]$. Exercise leaders (i.e. instructors) may be an important influence on behaviour of individuals who attend exercise classes (groups), and it has been suggested that the social 
identity approach to leadership (SIL) could add substantial value to research in exercise settings [6,7]. For instance, SIL places the group processes inherent within exercise class settings at its analytical heart. According to SIL $[27,28]$ effective leaders are: (1) in-group prototypes ('prototypicality' - exemplifying the group and what makes it different); (2) ingroup champions ('advancement' - promoting the good of the group); (3) entrepreneurs of identity ('entrepreneurship' - defining the shared beliefs and values); and (4) embedders of identity ('impresarioship' - providing opportunities for the desired collective behaviour). Through these four behaviours leaders are able to mobilise followers by recruiting and maintaining the allegiance and support of other group members. In the context of exercise, a class instructor may therefore be able to mobilise followers to attend classes. It is possible to hypothesise that individuals attending exercise classes who perceive their instructor to demonstrate identity leadership behaviours may be more likely to have greater class adherence.

Until recently, there was limited direct research as to the relevance of SIL in exercise settings. A small number of studies have now begun to examine the relationship between both identity leadership behaviours and group identification in exercise participants $[7,9,20]$. Stevens et al. [7] found a small significant association between identity leadership behaviours and attendance in exercise class attendees. However as previously noted, the study measured attendance via proportional frequency as opposed to by tenure/adherence, making predictions about applicability for long-term participation potentially difficult. In a follow-up study, Stevens et al. [9] used a 2-wave design to show that perception of identity leadership behaviours at study outset predicted group identification 8 -weeks later and, that this group identification was associated with attendance. These findings provided support for the suggestion that identity leadership behaviours influence attendance via group identification temporally. Yet, this study examined members of amateur sports teams - not 
exercise classes. Support for SIL specifically within a group exercise context has recently been offered by Steffens et al. [20], who demonstrated that identity leadership behaviours were associated with more frequent class attendance (in the previous 4 weeks) via stronger group identification. Thus, whilst evidence is growing that identity leadership behaviours may engender exercise class attendance, and that this may occur via group identification, empirical evidence regarding group exercise classes specifically is limited and offers scope for further investigation, particularly in terms of adherence as measured by tenure, and future intentions to continue to adhere.

\section{Relational Identification}

A distinct yet related concept to group identification is that of relational identification [29,30]. Sluss and Ashforth [29] suggest that even within a group, we form one-to-one role-relationships with others, and that the impact of these relationships has been overlooked in leadership research. Sluss and Ashforth outlined relational identification as the extent to which we define ourselves in terms of a given role-relationship. In the context of an exercise class and the present study, an individual may identify themselves in the context of the relationship between themselves, as the class attendee, and the class instructor (i.e. leader). It is suggested that as two people get to know each other they become 'personalised' over time, thus affecting their interactions (behaviours) within the rolerelationship. Sluss and Ashforth propose that relational identification may lead to identification with groups that are shared by the individuals in the role-relationship via generalisation. Thus, relational identification may lead to group identification.

Sluss et al. [31] offered support for the association between relational and group identification, and found that this was especially the case when the leader was viewed as 'prototypical'. In contrast, Steffens et al. [30] found that identification with a group may lead to relational identification with a leader, and that the group provides the framework for 
the relationship. It is plausible therefore that interaction in both directions may take place.

Whilst neither of the aforementioned studies pertained to an exercise situation, relational identification to leaders has been shown to be associated with follower mobilisation of effort in an elite sport context [32] and thus it is possible, but not yet known, that this may also apply to exercise.

Since prototypicality is proposed as an element of identity leadership behaviour, its potential involvement makes way for the possibility that group identification, identity leadership, and relational identification may all be associated with, or predict, exercise class adherence. As 'personalisation' takes place over time and influences behaviour, and with potential multi-directional interactions at hand, a group exercise class attendee may both identify more strongly with a class or leader they have attended/known for longer and/or attend for longer when they identify more strongly with the leader or class. If both: (1) relational identification with an exercise class instructor may affect behaviour/effort, and lead to group identification with the exercise class; and (2) group identification with the class may affect behaviour/adherence (through norms/values), and lead to relational identification with the class instructor; we propose that it is a step forward, and logical, to examine all three factors (group identification, identity leadership behaviours and relational identification) together in a single study. Presently, this has not been examined.

\section{The Present Research}

With group exercise classes a potentially important way of encouraging exercise participation, and the social identity approach an increasing area of interest with regards to physical activity adherence and leadership, the present study examined the associations between group identification, identity leadership, relational identification, and exercise class adherence. We also aimed to examine the potential relevance of multi-dimensional factors of group identification. The study partially replicated that of Stevens et al. [7] but expanded 
upon it in four main ways. First, through measurement of class adherence by tenure and expected future participation as opposed to attendance by volume. Second, through the inclusion of relational identification as a potential predictor. Third, by inclusion of a multidimensional measure of group identification in addition to a global measure, and fourth, through focussing solely on group exercise class attendees.

Based on previous research, it was expected that participants' group identification with the exercise class (H1a), perceived identity leadership behaviours of the class instructor (H1b), and relational identification with the class instructor (H1c) would be associated with the length of time participants had attended the exercise class. We also predicted that each of the independent variables (respectively $\mathrm{H} 2 \mathrm{a}, 2 \mathrm{~b}$, and $2 \mathrm{c}$ ) would predict participant expected likelihood of future attendance. These formed our primary hypotheses. A secondary hypothesis was that the multi-dimensional elements of group identification may show differing relationships with length of class attendance (H3).

It was anticipated that the findings may both support and offer new insights regarding the potential role of identification in exercise adherence. From a practical perspective, our research, and others', may ultimately contribute to recommended design and marketing of exercise classes, as well as the training provided to class instructors to promote long-term adherence of attendees.

\section{Method}

\section{Participants and Design}

Participants were 120 U.K. based adult exercise class attendees (male: $n=13$, female: $n=107)$ aged between 18 and 71 years $(M=40.11, S D=11.27)$. Participants were part of a range of exercise class types (see Table 1), and attended classes between "once every 2 weeks" and "more than 3 times per week", with the majority $(n=61)$ attending once per week (see Table 2). Participants who attended classes with more than one regular instructor 
were excluded from the study. A cross-sectional survey was conducted online and was open for participant completion from March to October 2019. Use of a cross-sectional survey design aligned with that used by Stevens et al. [7] allowing for partial replication and expansion of their findings. Participants took an average of 10 minutes and 34 seconds to complete the survey, which aligned with the researchers' expected timeframe.

209 Table 1.

210 Participants by Exercise Class type

211

\begin{tabular}{|c|c|}
\hline Class type & $\begin{array}{l}\text { No. } \\
\text { Participants }\end{array}$ \\
\hline Aerial Aerobics & 1 \\
\hline Barre & 1 \\
\hline Body Attack & 1 \\
\hline Body Balance & 5 \\
\hline Body Combat & 3 \\
\hline Body Conditioning & 1 \\
\hline Body Pump & 4 \\
\hline Bootcamp & 1 \\
\hline Boxercise/Box Fit & 5 \\
\hline Circuits & 9 \\
\hline Crew & 1 \\
\hline CrossFit & 1 \\
\hline Dance/Dance Fitness & 2 \\
\hline Drum Fit & 1 \\
\hline General Workout & 1 \\
\hline HIIT & 23 \\
\hline Insanity & 2 \\
\hline Jazzercise & 1 \\
\hline Kettlebells & 2 \\
\hline Kickboxing & 1 \\
\hline Legs, Bums and Tums & 1 \\
\hline Over 50s Ballet & 1 \\
\hline Pilates & 19 \\
\hline Running & 1 \\
\hline Spinning & 15 \\
\hline Triple Challenge & 1 \\
\hline
\end{tabular}


Yoga 10

Zumba 6

213 Table 2.

214 Participants by Frequency of class attendance

215

\begin{tabular}{lc}
\hline Attendance Frequency & $\begin{array}{l}\text { No. } \\
\text { Participants }\end{array}$ \\
\hline More than 3 times per week & 5 \\
3 times per week & 15 \\
Twice per week & 35 \\
Once per week & 61 \\
Once every two weeks & 4 \\
\hline
\end{tabular}

216

Power tables in Clark-Carter [33], indicated that for an $R^{2}$ value of 0.148 (based on

Stevens et al.'s [7] study examining identity leadership, group identification, and exercise class attendance), with 3 predictors (representing; group identification, identity leadership behaviour, and relational identification) a sample size of 60 is required to achieve power of .80 .

\section{Procedures}

The study was granted ethical approval by an Institutional Ethics committee. A small pilot study $(n=4)$ was conducted in March 2019. The process of collecting the participant data was without issue and procedures remained as planned. Voluntary and snowball sampling were used for participant recruitment. A link to an online survey was posted on social media (Facebook, Twitter, LinkedIn) and the primary researcher's own website. Participants could also share the link to reach other potentially suitable and interested participants.

Individuals were invited to visit the link which took them to the participant information sheet. They were then given the option to continue to the survey and by doing so, provided informed consent for participation. This method of consent aligned with that by 
Stevens et al. [7] (where consent was assumed through survey completion) and British

Psychological Society [34] guidelines for low risk studies. Participants completed demographics questions (age, gender, location, frequency of class attendance) and inclusion/exclusion criteria questions. Participants were asked the type of class which they would be answering the questions in relation to (if they attended multiple classes, they were requested to answer in relation to one only) and to confirm that the class had one regular class instructor. Participants subsequently completed the questionnaires; length of attendance to date, expected likelihood of future attendance, group identification, social identity leadership behaviour and relational identification. The final page of the survey acted as a participant debrief.

\section{Measures}

Group identification. To assess participants' identification with their exercise group, and replicate Stevens et al. [7], a four-item measure of social identification recommended by Postmes et al. [35] was used. Participants rated four statements on a 7-point Likert scale from 1 (fully disagree) to 7 (fully agree). The statements were 'I feel committed to my exercise group', 'I am glad to be a member of my exercise group', 'Being a member of my exercise group is an important part of how I see myself' and 'I identify with my exercise group'. Higher scores indicated higher levels of identification with the group. This measure has demonstrated good internal consistency in previous studies $[7,20]$ and likewise did so in the present study (Cronbach's $\alpha=.87$ ).

Multi-dimensional group identification. A multi-dimensional measure of identification enabled investigation of H3. The social identity for sport questionnaire (SIQS; [21]) has been developed in-line with theory and tested to enable measurement of social identification by three factors; ingroup ties, cognitive centrality, and ingroup affect. The scale's 9-items were adapted to fit the context of the study with the word 'team' being 
replaced with 'exercise class' (e.g. 'I feel strong ties to other members of this exercise class', 'In general, I'm glad to be a member of this exercise class'). Participants rated the items to indicate how they felt about being part of the exercise class from 1 (strongly disagree) to 7 (strongly agree). Higher scores indicated higher levels of the element of social identification being measured. Although in an exercise class as opposed to sport team context, the use of the SIQS was considered as having the potential to add insight, and be the first application of this scale in an exercise context. In view of this, a three-factor (i.e., three subscales of the SIQS) confirmatory factor analyses (via R software 4.0.2) using chi-square $\left(\chi^{2}\right)$, the robust CFI, the robust Tucker-Lewis index, the robust root mean square error of approximation with a 90\% confidence interval (RMSEA), and the standardized root mean square residual (SRMR; [36]) confirmed acceptable fit $(\chi 2=57.885, p<.001$, Robust CFI $=.960$, Robust $\mathrm{TLI}=.940$, Robust $\mathrm{RMSEA}=.108, \mathrm{SRMR}=.054)$. All factor loadings were above .76. The SIQS has been shown as being reliable with good construct validity [21]. The present study illustrated good internal consistency for each of the three sub-scales; ingroup ties, cognitive centrality, and ingroup affect; with Cronbach's $\alpha=.92, .87$, and .91 respectively.

Identity leadership. The Identity Leadership Inventory (ILI: [37]) assessed participants' perceived SIL behaviour of their class instructor. Comprising 15-items, this scale was developed to measure identity leadership, as per the theory, both globally and by the four-facets proposed by Haslam et al. [27]: prototypicality, advancement, entrepreneurship and impresarioship. Participants were asked to rate the extent to which their exercise class instructor engaged in the behaviours/activities described by each of the fifteen statements (e.g. 'the class instructor is a model member of the class', 'the class instructor creates a sense of cohesion within the class') on a 7-point Likert scale from 1 (not at all) to 7 (completely). Higher scores indicated a higher level of engagement in identity leadership. The ILI has demonstrated good construct validity both during development [37] and across 
20 countries [28]. Identity leadership research in exercise settings has used the ILI [7] and shown good internal consistency. Cronbach's $\alpha$ in the present study showed excellent internal consistency $(\alpha=.94)$ for both the global measure and the four facets $(\alpha=.89, .90$, $.91, .82$ respectively).

Relational identification. To measure participants relational identification with their exercise class instructor, we adapted a 10 -item measure from previous studies $[38,39]$. Ten statements (e.g. 'When I talk about my class instructor, I usually say 'we' rather than 'him or her' and 'The values of my class instructor are consistent to my own') were rated on a 7point Likert scale from 1 (strongly disagree) to 7 (strongly agree). Higher scores indicated greater levels of relational identification.

Whilst the measure selected was intended for a workplace context, limited research on relational identification in exercise settings rendered scale selection challenging. Slater et al. [32] used a three-item measure of relational identification in an elite sports context.

However, this measure was intended primarily as a manipulation check and has not been used elsewhere in the literature. The more widely used 10-item measure was therefore selected and adapted to reference the 'class instructor' in place of 'supervisor'. The measure has shown good internal consistency in previous research $[38,39]$ and also did so in the present study (Cronbach's $\alpha=.91)$. Given that this was the first use of this measure of relational identification in an exercise setting, unidimensional confirmatory factor analyses were run, which evidenced non-acceptable model fit $(\chi 2=146.842, p<.001$, Robust CFI $=.846$, Robust TLI $=.802$, Robust RMSEA $=.163$, SRMR $=.078)$. Despite unsatisfactory fit, all factors loadings were above $.40[40]$. Nevertheless, relational identification results should be interpreted with caution.

Length of exercise class attendance to date. Participants indicated how long they had been attending the exercise class in relation to which they were answering the survey. It 
was felt that 'weeks' attendance would be too granular for longer term attendees to recall and report accurately, and that 'years' would not capture shorter term attendees. Thus, in an attempt to balance obtaining data that was as accurate and granular as possible whilst ensuring clarity for participant completion, months were selected as the attendance units. Participants selected from a drop-down list ranging from $1-60$ months, with additional options of 'less than 1 month' and 'more than 5 years' (thus a total of 62 options were available). Selection of either of the two latter options elicited a free-format follow up box in which participants indicated the length of time they had attended. Data provided in this latter circumstance was subsequently converted to months (e.g., 2 weeks $=0.5$ months) prior to analysis to ensure consistency of units.

Expected likelihood of future attendance. Measurement of anticipated future participation in a cross-sectional study poses some issues since intention may not accurately predict behaviour [41]. Additionally, there has been debate in the literature regarding the use of 'intention' versus 'expectation' [42-45]. Meta-analysis by Sheppard et al. [44] indicated that expectation was more highly correlated to behaviour than intention. In research directly relating to physical activity (taking a walk) Warshaw and Davis [45] showed expectation to be a significantly better predictor of behaviour than intention and more recently expectation has been shown as more highly correlated to other health behaviours (alcohol consumption \& sustained weight loss) [42]. As such, expected likelihood of future attendance was considered the most appropriate measure.

Courneya and McCauley [43] defined expectation as the "likelihood of the behaviour being performed whether or not an intention exists" (p.53). Adapted from research conducted by Spink [46] our participants were asked 'How likely are you to continue attending the exercise class for the foreseeable future?'. Fixed-choice responses available 
were: (1) Not likely at all (at or near $0 \%$ chance); (2) Not likely ( $25 \%$ chance or less); (3) SoSo (50\% chance); (4) Likely (75\% chance or better); or (5) Very Likely (at or near 100\%).

\section{Data Analysis}

To assess $\mathrm{H1} \mathrm{a}, 1 \mathrm{~b}$, and $1 \mathrm{c}$, a forced entry multiple regression was used to establish whether group identification, identity leadership and/or relational identification were associated with length of class attendance. To establish whether the three predictor variables were associated with expected likelihood of future attendance (H2a, 2b, and 2c), an ordinal regression was planned. Inspection of the data revealed the majority of participants $(97 \%, n$ $=116$ ) had selected only two of the potential five answer categories ('at or near $100 \%$ ' likely and ' $75 \%$ or better'). Faced with this unexpected scenario and with an ordinal regression no longer viable, a decision was taken to instead examine participants who were 'at or near $100 \%$ ' likely to continue $(\mathrm{n}=90)$ vs those who were not $(\mathrm{n}=30$ - comprising: $75 \%$ chance or better, $\mathrm{n}=26 ; 50 \%$ chance, $\mathrm{n}=3 ; 0 \%$ chance, $\mathrm{n}=1$ ) using a binary logistic regression. Although not ideal, given the focus on adherence, a distinction between participants who reported being $100 \%$ likely to continue and those who did not, was felt to have potential practical relevance. Forced entry was selected due to the limited amount of previous research on exercise, none containing all three of the potential predictors to be investigated, and since we were interested in which of the three predictors, group identification, identity leadership or relational identification, was most strongly associated with class tenure. To address $\mathrm{H} 3$, correlational analysis was used to assess whether the three SIQS elements showed differing relationships with length of class attendance.

\section{Results}

\section{Preliminary Analysis}

Scatter plots for group identification, identity leadership and relational identification (predictor variables) against length of class attendance (continuous outcome variable) were 
run to ensure the relationships were not curvilinear. $\mathrm{Z}$ scores identified outliers as those with values over 3.29 [47]. Three values for length of class attendance and one value for identity leadership met the criteria and, the researcher being satisfied that this data was from the population being studied, were winsorized. P-P plots to check for normality revealed potential skew, particularly for identity leadership and length of class attendance. This was potentially not a concern due to the sample size being over 30 [47]. ZResid vs ZPred and partial plots revealed potential funnelling and a possible violation of homoscedacity with the identity leadership variable. The assumption of independent errors was checked using the Durbin-Watson statistic which was close to 2 (2.06). Collinearity between predictors was not considered an issue since the correlation coefficient between the predictors were all below .8 , with the highest being between identity leadership and relational identification $(r=.68)$. Additionally, the VIF values for the predictors were all well below 10 (highest $=2.114$ ) and tolerance values above .2 . The average VIF was 1.98 which was close to 1 . Inspection of the residuals revealed no cases had a Mahalanobis distance of $>15($ largest $=13.419)$, none had Cooks distance $>1(\max =.151)$ and DFBETA statistics were all $<1$. It was concluded that extreme cases were unlikely to provide undue influence. The assumption of linearity between the predictor variables and their logits (required for binary logistic regression) was met since no interactions were significant $(p>.05)$. The means and standard deviations of the continuous variables are shown in Table 3 .

Table 3.

Means and standard deviations of continuous variables

\begin{tabular}{lll}
\hline & $M$ & $S D$ \\
\hline
\end{tabular}

Length of Class Attendance (months)

Group Identification 
Identity Leadership

Relational Identification
379

380

381

382

\section{Main Analysis}

Multiple regression. Multiple linear regression analysis to test whether group identification, identity leadership, or relational identification significantly predicted participants' length of class attendance showed a non-significant regression equation $(F(3,116)=.795, p=.499)$ with a small effect size $(r=.142)$ (See Table 4). The three predictors explained $2.0 \%$ of the variation in length of class attendance $\left(R^{2}=.020\right)$. This suggests that other factors are involved since $98.0 \%$ is unexplained by the model. None of the three predictors significantly predicted length of class attendance; group identification $(\beta$ $=.004, p=.974)$, identity leadership $(\beta=.163, p=.222)$, relational identification $(\beta=-.037$, $p=.780)$. In sum, $\mathrm{H} 1 \mathrm{a}, 1 \mathrm{~b}$, and $1 \mathrm{c}$ were not supported.

Table 4.

Linear model of predictors of length of class attendance with $95 \%$ confidence intervals reported in parenthesis.

\begin{tabular}{lcccc}
\hline & $B$ & $S E B$ & $\beta$ & $P$ \\
\hline Constant & 5.951 & 12.205 & & .627 \\
Group Identification & $(-18.223,30.125)$ & & & \\
Identity Leadership & $(-3.971,4.103)$ & 2.038 & .004 & .974 \\
Relational Identification & 3.709 & & & .222 \\
\hline & $(-2.276,9.693)$ & 3.022 & .163 & .222 \\
& $(-5.717,4.302)$ & 2.529 & -.037 & .780 \\
\hline
\end{tabular}

Note. $R^{2}=.020, p=.499$

Binary logistic regression. Binary logistic regression tested whether group identification, identity leadership or relational identification could significantly predict 


\begin{tabular}{lcccc}
\hline & $B$ & SE B & $P$ & Odds Ratio \\
\hline Constant & -2.397 & 1.133 & .034 & 0.091 \\
Group Identification & .301 & .193 & .118 & $\begin{array}{c}1.352 \\
\text { Identity Leadership }\end{array}$ \\
Relational Identification & .632 & $.926,1.973)$ \\
\hline
\end{tabular}

whether participants were at or near $100 \%$ likely to continue attending their exercise class for the foreseeable future vs less than at or near $100 \%$ likely to continue (H2). Results showed a significant regression equation (chi-square $=12.918, d f=3, p=.005$ ) indicating that the model provided a significantly better prediction than those made purely on which category occurred most frequently. The model explained $15.1 \%$ of the variation in outcome (pseudo $\left.R^{2}=.151\right)$ and the Hosmer and Lemeshow test indicated a good fit (chi-square $=6.531, d f=$ $8, p=.588)$. Group identification showed a non-significant positive effect $(b=.301$, Wald $=$ 2.443, $d f=1, p=.118)$, identity leadership showed a significant positive effect $(b=.632$, Wald $=4.926, d f=1, p=.026)$, and relational identification showed a non-significant negative effect $(b=-.324$, Wald $=1.685, d f=1, p=.194)$ on likelihood of continued participation being at or near $100 \%$ (see Table 5). H2b was therefore supported but $\mathrm{H} 2 \mathrm{a}$ and $2 \mathrm{c}$ were not. Table 5 summarises the results.

Table 5.

Model of predictors of likelihood of future participation with 95\% confidence intervals reported in parenthesis.

Note. Pseudo $R^{2}=.151, p=.005$

The analysis indicated that for every increase of 1 unit in identity leadership score it is 1.9 times more likely that someone will be 'at or near $100 \%$ ' likely to continue attending their exercise class for the foreseeable future versus not. The confidence interval for the odds 
ratio did not span 1, indicating the direction of the observed relationship is likely to be true in the population sampled. The confidence intervals for the odds ratios of group identification and relational identification did span 1, providing ambiguous directional results.

Correlation. Pearson's correlation coefficients were used to examine whether there were differences in the associations between the three elements of multi-dimensional group identification measured by the SIQS and the length of class attendance to date (H3). Results showed a small effect approaching significance for ingroup ties $(r=.165, p=.072)$, a negligible non-significant negative effect for cognitive centrality $(r=-.051, p=.579)$ and a negligible non-significant effect for ingroup affect $(r=.010, p=.910)$. This provided partial support for $\mathrm{H} 3$ as there appeared to be marginal differences, both in effect size and direction, across the elements.

Table 6.

Correlation matrix of study variables

\begin{tabular}{|c|c|c|c|c|c|c|c|c|}
\hline Variable & 1 & 2 & 3 & 4 & 5 & 6 & 7 & 8 \\
\hline 1. Group identification & - & $.66^{* *}$ & $.70 * *$ & $.73 * *$ & $.60 * *$ & $.61^{* *}$ & .08 & $.30^{*}$ \\
\hline 2. Ingroup ties & & - & $.51 * *$ & $.57 * *$ & $.63 * *$ & $.48 * *$ & .17 & $.19 *$ \\
\hline 3. Cognitive centrality & & & - & $.63 * *$ & $.47 * *$ & $.47 * *$ & -.05 & $.19^{*}$ \\
\hline 4. Ingroup affect & & & & - & $.56 * *$ & $.54 * *$ & .01 & $.35 * *$ \\
\hline 5. Identity leadership & & & & & - & $.68 * *$ & .14 & $.32 * *$ \\
\hline 6. Relational identification & & & & & & - & .08 & .16 \\
\hline 7. Exercise to date (months) & & & & & & & - & $.26^{*}$ \\
\hline 8. Future likelihood & & & & & & & & - \\
\hline
\end{tabular}
Note. $* p<.05 ; * * p<0.001$.

433 Future likelihood coded as $0=$ Not likely at all (at or near 0\%); $1=$ So-so (50\% chance); 2 $434=$ Likely (75\% chance or better); and 3 = Very likely (at or near 100\%). 
identification as measured by SIQS showed potential to have differing relationships with length of class attendance to date, and that identity leadership appeared to be associated expected likelihood of future attendance, a binary logistic regression was conducted to establish if the three elements of SIQS might significantly predict likelihood of future attendance. The assumption of linearity of the logits of the predictors was met, as was the assumption of multicollinearity (Tolerance values all $>.1, \mathrm{VIF}<10, \mathrm{r}<.8$ ). P-P plots appeared to indicate normality, with possible skew for ingroup affect. The regression showed a significant equation (chi-square $=12.397, d f=3, p<.01)$ indicating that the model provided a significantly better prediction than those made purely on which category occurred most frequently. The model explained $14.5 \%$ of the variation in outcome (pseudo $R^{2}=.145$ ) and the Hosmer and Lemeshow test indicated a good fit (chi-square $=9.167, d f=8, p=$ .328). Ingroup affect showed a significant and positive effect $(b=.672$, Wald $=7.500, d f=$ $1, p=.006)$, ingroup ties showed a non-significant negative effect $(b=-.079$, Wald $=.174, d f$ $=1, p=.677)$, and cognitive centrality showed a non-significant negative effect $(b=-.059$, Wald $=.1081, d f=1, p=.742$ ) on likelihood of continued participation being at or near 100\% (see Table 7).

Table 7.

Model of predictors of likelihood of future participation with 95\% confidence intervals reported in parenthesis.

\begin{tabular}{lcccc}
\hline & $B$ & SE B & $P$ & Odds Ratio \\
\hline Constant & -2.011 & .995 & .043 & 0.134 \\
Ingroup Ties & -.079 & .188 & .677 & 0.924 \\
& & & & $(.639,1.337)$ \\
Cognitive Centrality & -.059 & .179 & .742 & .943 \\
& & & & $(.664,1.339)$
\end{tabular}


Ingroup Affect

Note. Pseudo $R^{2}=.145, p<.01$

The analysis indicated that for every increase of 1 unit in ingroup affect score it is 2.0 times more likely that someone will be 'at or near $100 \%$ ' likely to continue attending their exercise class for the foreseeable future versus not. The confidence interval for the odds ratio did not span 1, indicating the direction of the observed relationship is likely to be true in the population sampled. The confidence intervals for the odds ratios of ingroup ties and cognitive centrality did span 1 , providing ambiguous directional results.

\section{Discussion}

The goal of our study was to provide further support for the applicability of the social identity approach to physical activity, specifically in the context of group exercise class adherence and leadership. Additionally, we expanded on previous research $[7,20]$ through examination of the potential relevance of relational identification and multi-dimensional factors of group identification. We sought to discover whether group identification, identity leadership and/or relational identification may predict exercise class adherence, as measured by length of class attendance to date and/or expected likelihood of future participation. We found that neither group identification, identity leadership behaviour nor relational identification were associated with length of class attendance to date. H1a, $1 \mathrm{~b}$ and $1 \mathrm{c}$ were not supported. We did find support for $\mathrm{H} 2 \mathrm{~b}$, as identity leadership behaviour was positively associated whether exercisers reported being 'at or near 100\%' likely to continue attending their class vs not. Since neither group nor relational identification were associated with continuation likelihood, H2a and 2c were not supported.

The results appear to be at odds with previous work $[7,9,20]$ which has suggested that identity leadership behaviour may influence group physical activity attendance via group 
identification. The fact that neither of these variables were shown to be associated with the length of exercise class attendance to date in the present study may shed a slightly different light. Whilst mediational analysis was not conducted in the present study, this alone would not likely account for the lack of findings. One explanation of our findings could relate to how we examined attendance. Previous studies have examined attendance by volume/frequency as opposed to tenure. Our findings open the possibility that length of exercise class attendance and volume of attendance when a person is minded to attend may be distinct exercise adherence related constructs, each with differing relationships to group identification, identity leadership, and/or relational identification. Equally, it could be that these predictors are more impactful or relevant in a sport context compared to exercise or that exercise class leaders are less aware of behaviour that may engender group identification, due to the lack of training and research in the area. Future longitudinal studies involving the development and application of interventions (e.g., the 3Rs: Reflect, Represent, Realise; [27]) aimed at increasing both identity leadership behaviour and group identification, whilst also measuring group identification and attendance both via frequency and length as well as examining drop-out rates may help to provide a clearer understanding. Identity leadership behaviour was however shown to be a significant predictor of participants' expectations being 'at or near 100\%' likely to continue attending their class. For every unit increase in identity leadership score participants were 1.9 times more likely to be 'at or near $100 \%$ ' likely to continue vs not. This finding partly aligns with the previous research evidence that has shown identity leadership behaviour to be associated with more frequent attendance in both exercise classes [20] and amateur sports teams [9]. However, it does not align with other results in the current study that identity leadership did not predict length of class attendance. 'Expectation' of future behaviour has been shown correlate more closely to actual behaviour in a variety of health behaviours $[42,45]$ and as such the finding 
that identity leadership was associated with greater expected likelihood of future participation, specifically in exercise class attendees, was as predicted, and accordingly, has practical relevance (although it is important to remember this particular study does not permit causational establishment). Since group exercise classes offer a gateway to exercise [4] the possibility that identity leadership behaviour might enhance expected or actual continuation of participation could have important practical implications for increasing physical activity adherence. Further research in this regard appears warranted as it may offer an important angle for inclusion of identity leadership behaviours in exercise instructor training.

The finding that relational identification with the exercise instructor did not appear to be related to adherence in the present study was not as expected. Relational identification was not found to be associated with either length of class attendance to date or future expected participation. Although this could indicate that relational identification with the class instructor is not a relevant factor in the adherence of exercise class attendees, it could equally be that the measure used was not suitable for an exercise context. Measure selection was limited and that used had only been done so previously in workplace settings $[38,39]$. The development and validation of a relational identification measure specifically for exercise class settings may help to enhance understanding and future work in this area. Given the strong theoretical links to group identification and identity leadership, the null finding in this study alone would seem insufficient to rule out a potential role for relational identification regards exercise adherence.

Whilst no significant results were shown in relation to the global measure of group identification, the study additionally aimed to explore the possibility that multi-dimensional elements, as measured by the SIQS [21] may relate differentially to exercise class adherence. It appeared that this may be the case. Initial correlational analysis showed that the three elements had differing relationships with length of class attendance and whilst none were 
significant, small effects were observed for ingroup ties. Of particular interest was follow-up analysis indicating that ingroup affect (which specifically measures how good people feel about being a member of a group) was significantly associated with whether participants were 'at or near $100 \%$ ' likely to continue vs not. For every unit increase in ingroup affect score participants were 2.0 times more likely to be 'at or near $100 \%$ ' likely to continue to exercise in the class. This finding, whilst exploratory in nature, expands on previous research indicating the importance of group identification on exercise class attendance by highlighting that it may be the specific element of identity relating to how good a person feels about being a member of a group that could enhance expected adherence. This aligns with research in the field of sport suggesting that the different elements measured by SIQS may relate to different outcomes $[21,24]$. Clearly the small scale and cross-sectional nature of this study does not enable any firm conclusions, but does suggest that further research on exercise adherence utilising SIQS might enhance present understanding.

\section{Further Limitations and Considerations}

Whilst the present study has yielded some interesting and perhaps unexpected results, there are limitations to note. First, the sample examined may not have been representative of the group exercise class attendee population and may not be generalisable due to voluntary and snowball sampling. Indeed, it is possible that only those more enthusiastic about their class responded. This was borne out by the majority of participants (97\%) selecting ratings of either 'at or near $100 \%$ ' or ' $75 \%$ or more' likely to continue. An alternative sampling approach whereby classes are approached as a whole and attended in person by the researcher, such that all attendees from a class are given an opportunity to participate, may help address this were the study to be repeated. This is partially akin to the approach adopted by Stevens et al. [7] and could explain the difference in findings. A systematic approach with 
sufficient sample sizes could allow researchers to examine differences across exercise class types.

Further regarding generalisability, the participants comprised primarily females (89\%) affording the possibility that the findings may not be as applicable for male class attendees. The greater number of female respondents was perhaps unsurprising, since research has suggested that female:male class attendance is in the region of 5:1 [48]. From a practical standpoint, since more males than females are presently meeting physical activity guidelines [49] opportunities to promote exercise activity by females may be of particular importance. Third, our study was cross-sectional and relied on self-report data. We asked participants how long they had attended the exercise class, but how objectively accurate this was is unknown. The use of a longitudinal design may partially eliminate this issue since attendance could be recorded and measured over a known period. Coupling this with attendance register records, may also add rigor. The cross-sectional nature of this research means that whilst it may be speculated that group identification by way of ingroup affect may positively affect group exercise class adherence (expectation to continue), no causal link can be established. Instead, our research should be seen as an important stepping stone in terms of examining the multi-dimensional conceptualisation of group identification in exercise settings.

Fourth, in an attempt to partially replicate and expand on Stevens et al. [7], we elected to use length of exercise class attendance to date as a dependent variable, in place of exercise class attendance frequency. The aim of this was to allow comparison between results from volume versus length of attendance data in a comparable cross-sectional study. In view of this we chose not to additionally use length of class attendance as a control variable in the first step of the expected future attendance regression. Controlling for attendance length in a future study of expected class attendance continuation may provide additional insight. 
Finally, although SIL behaviour showed a significant result in terms of predicting likelihood of continued participation, mis-matched group sizes meant that $75 \%$ would have been predicted correctly through chance alone. Binary logistic regression was undertaken in place of the planned ordinal regression since most participants selected only two of the five available likelihood categories, with greater number choosing 'at or near $100 \%$ '. Thus, whilst the regression model with predictors offered a significant improvement, the prediction percentage increased by just $2 \%$ to $77 \%$. For ingroup affect, this was even smaller, from $75.0 \%$ to $75.8 \%$. Further research, ideally with more equal group numbers, would need to be conducted to check for replication.

\section{Conclusions}

The present study has provided partial support for a proposed role of SIL behaviour in the continued participation of exercise class attendees. Additionally, we present evidence that supports the proposition that the multi-dimensional elements of group identification may be associated differently with exercise class adherence. Ingroup affect appears most pertinent in this regard. Our study has also raised questions over whether the social identity approach is as applicable for exercise class adherence in terms of tenure as has previously been suggested in relation to attendance frequency/volume and indicates further investigation is warranted. The lack of support for a role of relational identification regards exercise class adherence in the present research should not preclude its investigation in future. Increasing activity levels amongst adults is of paramount importance, and we have provided initial evidence that the perceived leadership of 'our' exercise instructors, and ingroup affect may be determinants of whether 'we' will continue to attend our exercise classes.

The Authors declare that there is no conflict of interest. 


\section{References}

606

1. World Health Organisation. Health Topics: Physical Activity. http://www.who.int/topics/physical_activity/en/(2017, accessed 2 Feb 2019).

2. Public Health England. Press release: 6 million adults do not do a monthly 10 minute brisk walk. https://www.gov.uk/government/news/6-million-adults-do-not-do-a-monthly-brisk-10minute-walk (2017, accessed 2 Feb 2019).

3. Linke, SE, Gallo LC and Norman, GJ. Attrition and adherence rates in sustained vs. intermittent exercise interventions. Ann Behav Med 2011; 42: 197-209.

4. EMDUK. Sweating your assets (white paper). https://emduk.org/sweating-your-assets/ (2018, accessed 17 Jun 2019).

5. Rees T, Haslam SA, Coffee P, et al. A social identity approach to sport psychology: Principles, practice, and prospects. Sports Med 2015; 45: 1083-1096.

6. Stevens M, Rees T, Coffee P, et al. A social identity approach to understanding and promoting physical activity. Sports Med 2017; 47: 1911-1918.

7. Stevens M, Rees T, Coffee P, et al. Leaders promote attendance in sport and exercise sessions by fostering social identity. Scand J Med Sci Sports 2018; 28: 2100-2108.

8. Ellemers N, Gilder DD and Haslam SA. Motivating individuals and groups at work: A social identity perspective on leadership and group performance. Acad Manage Rev 2004; 29: $459-478$

9. Stevens M, Rees T, Coffee P, et al. Leading us to be active: A two-wave test of relationships between identity leadership, group identification, and attendance. Sport Exerc Perform Psychol. Epub ahead of print $1^{\text {st }}$ March 2019.

10. Tafjel H, and Turner JC. An integrative theory of intergroup conflict. In Austin WG and Worchel S (Eds.), The social psychology of intergroup relations. Monterey, CA: Brooks/Cole, 1979, pp.33-47. 
630

11. Turner JC, Hogg MA, Oakes PJ, et al. Rediscovering the social group: A selfcategorization theory. Oxford: Basil Blackwell, 1987.

12. Strachan SM, Shields CA, Glassford E, et al. Role and group identity and adjustment to the possibility of running group disbandment. Psychol Sport Ex 2012; 13: 436-443.

13. Evans MB, McLaren C, Budziszewski R, et al. When a sense of "we" shapes the sense of "me": Exploring how groups impact running identity and behavior. Self and Identity 2019; 18: $227-246$.

14. Burke SM, Carron AV, Eys MA, et al. Group versus individual approach? A metaanalysis of the effectiveness of interventions to promote physical activity. Sport Exerc Psychol Rev 2006; 2: 19-35.

15. Grant F, Hogg MA and Crano WD. Yes, we can: Physical activity and group identification among healthy adults. J Appl Soc Psychol 2015; 45: 383-390.

16. Terry DJ and Hogg MA. Group norms and the attitude-behavior relationship: a role for group identification. Pers Soc Psychol Bull 1996; 22: 776-793.

17. Stevens M, Rees T and Polman R. Social identification, exercise participation, and positive exercise experiences: Evidence from parkrun. J Sports Sci 2019; 37: 221-228. 18. Middleton KR, Anton SD and Perry MG. Long-Term Adherence to Health Behavior Change. Am J Lifestyle Med 2013; 7: 395-404.

19. Beauchamp MR. Promoting exercise adherence through groups: A selfcategorization theory perspective. Exerc Sport Sci Rev 2019; 47: 54-61.

20. Steffens NK, Slade EL, Stevens M, et al. Putting the 'we' into workout: The association of identity leadership with exercise class attendance and effort, and the mediating role of group identification and comfort, Psychol Sport Exerc, Epub ahead of print November 2019. DOI: 10.1016/j.psychsport.2019.101544. 
21. Bruner MW and Benson AJ. Evaluating the psychometric properties of the social identity questionnaire for sport (SIQS). Psychol Sport Exerc 2018; 35: 181-188.

22. McGowan M, Shiu E and Hassan LM. The influence of social identity on value perceptions and intention: Social identity and value perceptions. $J$ Consum Beh 2017; 16 : $242-253$.

23. Cameron JE. A three-factor model of social identity. Self and Identity 2004; 3: 239-262.

24. Bruner MW, Balish SM, Forrest C, et al. Ties that bond: Youth sport as a vehicle for social identity and positive youth development. Res Q Exerc Sport 2017; 88: 209-214.

25. Register of Exercise Professionals. New research reveals the impact fitness instructors have on client retention. https://www.exerciseregister.org/blog/post/new-research-revealsthe-impact-fitness-instructors-have-on-client\%20retention/ (2018, accessed 22 July 2019). 26. Slater MJ, Coffee P, Barker JB, et al. Promoting shared meanings in group memberships: A social identity approach to leadership in sport. Reflective Practice 2014; 15: 672-685. 27. Haslam SA, Reicher SD and Platow MJ. The new psychology of leadership: Identity, influence, and power. Hove: Psychology Press, 2011.

28. Van Dick R, Lemoine JE, Steffens NK, et al. Identity leadership going global: Validation of the identity leadership inventory across 20 countries. J Occup Organ Psychol 2018; 91: $697-728$.

29. Sluss DM and Ashforth BE. Relational identity and identification: Defining ourselves through work relationships. Acad Manage Rev 2007; 32: 9-32.

30. Steffens NK, Haslam SA and Reicher SD. Up close and personal: Evidence that shared social identity is a basis for the 'special' relationship that binds followers to leaders. Leadersh Q 2014; 25: 296-313. 
31. Sluss DM, Ployhart RE, Cobb MG, et al. Generalizing newcomers' relational and organizational identifications: Processes and prototypicality. Acad Manage J 2012; 55: 949975.

32. Slater MJ, Turner MJ, Evans AL et al. Capturing hearts and minds: The influence of relational identification with the leader on followers' mobilization and cardiovascular reactivity. Leadersh $Q 2018 ; 29: 379-388$.

33. Clark-Carter D. Quantitative Psychological Research: The Complete Student's Companion. Hove: Psychology Press, 2010.

34. British Psychological Society. Code of Human Research Ethics. https://www.bps.org.uk/news-and-policy/bps-code-human-research-ethics-2nd-edition-2014 2014, accessed 2 Feb 2019).

35. Postmes T, Haslam SA and Jans L. A single-item measure of social identification: Reliability, validity, and utility. Br J Soc Psychol 2013; 52: 597-617.

36. Hu LT and Bentler PM. Cutoff criteria for fit indexes in covariance structure analysis: Conventional criteria versus new alternatives. Struct Equ Modeling 1999; 6: 1-55. 37. Steffens NK, Haslam SA, Reicher SD et al. Leadership as social identity management: Introducing the identity leadership inventory (ILI) to assess and validate a four-dimensional model. Leadersh Q 2014; 25: 1001-1024.

38. Qu R, Janssen O and Shi K. Transformational leadership and follower creativity: The mediating role of follower relational identification and the moderating role of leader creativity expectations. Leadersh $Q 2015 ; 26: 286-299$. 39. Walumbwa FO and Hartnell CA. Understanding transformational leadership-employee performance links: The role of relational identification and self-efficacy. J Occup Organ Psychol 2011; 84: 153-172. 
40. Comrey AL and Lee HB. A first course in factor analysis. Hillsdale, NJ: Laurence Erlbaum Associates Inc, 1992.

41. Sniehotta FF, Scholz U and Schwarzer R. Bridging the intention-behaviour gap: Planning, self-efficacy, and action control in the adoption and maintenance of physical exercise. Psychol Health 2005; 20: 143-160.

42. Armitage CJ, Norman P, Alganem S, et al. Expectations are more predictive of behavior than behavioral intentions: Evidence from two prospective studies. Ann Behav Med 2015; 49: 239-246.

43. Courneya KS and McAuley E. Predicting physical activity from intention: Conceptual and methodological issues. J Sport Exerc Psychol 1993; 15(1): 50-62.

44. Sheppard BH, Hartwick J and Warshaw PR. The theory of reasoned action: A metaanalysis of past research with recommendations for modifications and future research. $J$ Consum Res 1988; 15: 325-343.

45. Warshaw PR and Davis FD. Disentangling behavioral intention and behavioral expectation. J Exp Soc Psychol 1985; 21: 213-228.

46. Spink KS. Cohesion and intention to participate of female sport team athletes. J Sport Exerc Psychol 1995; 17: 416-427.

47. Field A. Discovering Statistics using IBM SPSS Statistics. London: Sage, 2018.

48. Nielson. Global consumer exercise trends survey.

https://www.slideshare.net/Bryankorourke/nielsen-global-consumer-exercise-trends-survey2014 (2014, accessed 17 June 2019).

49. Statista. Physical activity levels by gender in England.

https://www.statista.com/statistics/326264/physical-activity-levels-by-gender-in-england/ (2016, accessed 17 June 2019). 